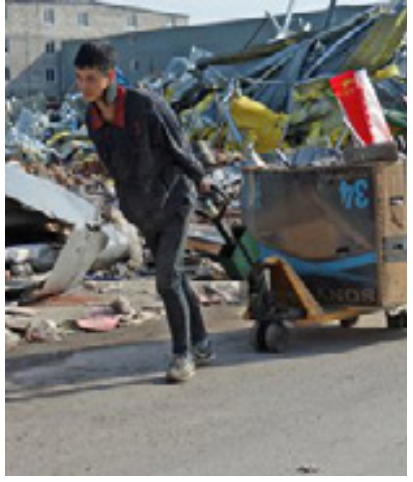

A man pulls his belongings in a cart in Daxing district (Beijing). Photo: Global Times.

\footnotetext{
The evictions were undoubtedly not just an unintended consequence of a disaster. They were preceded by the forced closing of shops, restaurants and housings in similar areas, and by the announcement of a plan to relocate Beijing's city government and public institutions to a nearby province.
}

\section{Eviction and the Right to the City}

Kevin Lin

Beijing's eviction of migrants from their dwellings in November 2017 following a deadly fire left tens of thousands homeless within days. It was rightly seen not as a legitimate response to a fire hazard but a convenient opportunity to push forward new political goals with regard to the city's migrant population. The evictions were undoubtedly not just an unintended consequence of a disaster. They were preceded by the forced closing of shops, restaurants and housings in similar areas, and by the announcement of a plan to relocate Beijing's city government and public institutions to a nearby province. This is part of a wider strategy to supposedly slow down the urban growth of the capital-moves that have produced heightened anxiety and uncertainty among the Chinese floating population. This poses the question: do migrants in today's China have a right to the city?

Significantly, those evicted comprised all kinds of migrants: e-commerce couriers, shop owners, street vendors, as well as IT professionals. This heterogeneity reflects the fact that Beijing is not an industrial city: much of its heavy industry has long been shut down or relocated to neighbouring provinces. In contrast to places like Shenzhen or Dongguan, where migrants are the bedrock of the local economy, migrants in Beijing are less central to economic activity, which may be one reason for the harsh measures undertaken by the authorities. However, migrants, if broadly defined as people from outside of Beijing, make up more than a third of Beijing's long-term residents, or over eight million people.

What the Beijing authorities might not have fully anticipated is that many who have obtained a Beijing hukou may continue to identify themselves as migrants, sharing not only the frustration of urban lives with other migrants, but also the feelings of being excluded and disposable. In one sense, migrant as a cultural identity cuts across the hukou line, which may explain why the phrase 'low-end' (diduan) touched a nerve for wide swaths of the population. So while the eviction speaks of a 'low-end population' (diduan renkou), the anxiety (and shared identity) extends beyond just rural migrant workers in the so-called 'low-end economy' (diduan jingji). 


\section{A common argument against eviction says that if those migrant workers who serve in the restaurants were forced to leave, there would be no one serving Beijing residents. The recognition of the role of migrant workers as servants and builders in a city like Beijing is simultaneously a factual statement and a reaffirmation of their 'low-end' socioeconomic position.}



The border of Houchang urban village in Beijing. Photo: Qiaochu Li.
Such shared sentiments may explain the outpouring of sympathy that followed the eviction (see Li, Song, and Zhang's essay in the present issue). But the form such sympathy takes may risk being paternalistic, and the paternalism of caring for the unfortunate can deepen the entrenchment of the social position of the migrant. A common argument against eviction says that if those migrant workers who serve in the restaurants were forced to leave, there would be no one serving Beijing residents. The recognition of the role of migrant workers as servants and builders in a city like Beijing is simultaneously a factual statement and a reaffirmation of their 'low-end' socioeconomic position. It can lead to the thoughtcomforting for the status quo-that so long as they are not evicted or treated too harshly, their lives on the margins need not be questioned.

Another notable and somewhat unexpected response came from civil society, offering a glimpse of a possible resurgence of the public voice. A public statement in late November signed by academics, independent intellectuals, lawyers, and other civil society activists evokes the language of legality, human rights, and constitutionalism, contending that the eviction of migrants 'is a serious case of violating the law and the constitution and impinging on human rights' (Wang 2017). A second statement released in December by eight legal scholars and lawyers called on the National People's Congress to review the constitutionality of the eviction, citing violations of five constitutional rights centred on land, housing, and private property rights (Weiquanwang 2017).

The framing of the rights of migrants as a liberalconstitutional issue related to property rights-a reminder of the once vocal constitutionalism movement of the 2000ssheds light on a largely unstated ideological contestation. The rights of migrant workers have been alternatively framed in relation to China's new working class's capacity to organise resistance by labour scholars and activists, or in terms of vulnerability of a social group in need of legal and constitutional protection by rights-oriented intellectuals. In practice, there is an overlap in labour and legal and citizenship rights, as can be seen from the fact that many labour scholars and activists also signed the first statement, where, for pragmatic reasons, a legalistic rights discourse is dominant. Still, such critique based on the protection of individual property rights leaves open the question of why evicted migrants are stuck in their place, socially and geographically, and of their collective rights.

There were acts of defiance in the form of sporadic collective protests and individual assistance to displaced migrants. One activist was detained and an organisation 
Will China's ambitious urban transformation

further deepen

tensions among the

urban population and

migrants? It is hard to

escape the conclusion

that, as such a policy

requires extensive

state intervention, the

eviction of migrants or

other harsh measures

will continue to recur. shut down; Hua Yong, a migrant artist who shot videos of the eviction, fled Beijing fearing for his safety, and was later detained and released. However isolated, these acts testify to the existence of alternative visions of what the city may look like, including the right for voluntary assistance to those in need, and documentation of abuses of power. Both are forbidden today.

The threat of urban protests was likely on the minds of the authorities. By some measure, China has one of the highest rates of urban riots. Many of them are expressions and assertions of the kind of city that the citizens want to see. Environmental protests to prevent polluting factories have resulted in some of the most successful mobilisations in recent years. Similarly, riots over the brutality of urban management officers (chengguan) have drawn wide support across the city. In light of this, the authorities have been pouring resources into pre-empting and containing urban riots.

Will China's ambitious urban transformation further deepen tensions among the urban population and migrants? It is hard to escape the conclusion that, as such a policy requires extensive state intervention, the eviction of migrants or other harsh measures will continue to recur. Still, there is hope that faced with this, more and more people will likely start to ask what kind of city they want and demand their right to the city. 